\title{
Herramientas TIC en la didáctica de arte y cultura visual
}

Learning tools for teaching art and visual culture

\author{
Ana Tirado-de la Chica ${ }^{1}$ \\ Universidad de Jaén
}

Recibido: 15.07 .2021

Aceptado: 20.09.2021

\section{Resumen}

Este trabajo aborda el uso de las TIC en la didáctica de las artes y la cultura visual. El objetivo principal se dirige a conocer la evaluación metodológica de la didáctica que progresivamente se ha experimentado en la docencia por la introducción de las TIC. La metodología es cualitativa de tipo descriptivo-exploratoria. Se adopta así una perspectiva auto etnográfica de la investigación orientada a la innovación docente y al cambio educativo. La muestra de estudio comprende la asignatura de Arte Infantil y Cultura Visual del Grado en Educación Infantil, y de Las Artes Plásticas y la Cultura Audiovisual en Educación Primaria del Grado en Educación Primaria de la Universidad de Jaén, para el periodo de 2016 hasta 2021. Los resultados muestran una relación de casos de actividades didácticas, según variables de contenidos y de recursos educativos digitales utilizadas. La discusión de los resultados y conclusiones se dirigen a las fortalezas y las debilidades de las metodologías docentes de esta experiencia, para una eficacia de la docencia en el uso de las TIC en materia de artes y cultura visual.

\footnotetext{
1 atirado@ujaen.es https://orcid.org/0000-0001-5761-7288
} 
Palabras clave: Educación Artística - Artes Visuales - Recursos Educacionales - TIC Método de Enseñanza.

\begin{abstract}
This work addresses the use of ICT in the didactics of the arts and visual culture. The main objective is aimed at knowing the methodological evaluation of didactics that has been progressively experienced in teaching due to the introduction of ICT. The methodology is qualitative, descriptive-exploratory. Thus, it adopts an auto-ethnographic perspective of research oriented to teaching innovation and educational change. The study sample consists of two subjects: one, Children's Art and Visual Culture of the Degree in Early Childhood Education; and Plastic Arts and Audiovisual Culture in Primary Education of the Degree in Primary Education of the University of Jaén, from 2016 to 2021. The results show some cases of didactic activities, according to variables of content and digital educational resources used. The discussion of the results and conclusions are directed to the strengths and weaknesses of the teaching methodologies of this experience, for an effective teaching in the use of ICT in the field of arts and visual culture.
\end{abstract}

Keywords: Art Education - Visual Arts - Learning Resources - ICT - Learning Methods. 


\section{Introducción}

Este trabajo es resultado del Proyecto de Innovación y Mejora Docente de la Universidad de Jaén (España) "Humanidades Digitales: competencias en Información y Alfabetización Informacional para docentes universitarios", PIMED25_202022. Se aborda la transformación digital de la docencia en materias de Artes y Cultura Visual, según la actualización de contenidos y recursos basados en las TIC. Esta investigación se ha realizado con motivo de la adaptación virtual de la docencia universitaria en España en el periodo de pandemia por covid19, y que ha correspondido al año académico 2020/2021. Así, desde noviembre de 2020 hasta abril de 2021, la modalidad de la docencia en las universidades españolas fue de $100 \%$ virtual, como medida de adaptación por covid-19. Esta situación de emergencia aceleró intensamente el proceso de digitalización y virtualización de la docencia universitaria para todas las materias y áreas de conocimiento, incluida la de Artes y Humanidades.

Si bien el proceso de introducción de las TIC en la docencia se inició desde hace más de diez años, esta ha estado más ligada a una modernización de las herramientas, pero, con frecuencia, esta no estuvo acompañada de una innovación de la metodología didáctica. Sin embargo, el confinamiento por covid-19 que se vivió en el último año nos situó en un escenario docente completamente TIC, y nos provocó directamente formular y responder una gran cantidad de preguntas y dudas sobre cómo adaptar la docencia universitaria con las TIC. El Marco Común de la Competencia Digital Docente en España se implantó hace apenas un año (INTEF, 2017; DGECT, 2020), si bien se empezó a trabajar anteriormente. Se organiza en torno a cinco áreas competenciales: Información y alfabetización informacional, Comunicación y colaboración, Creación de contenidos digitales, Seguridad y Resolución de problemas. Comprende 21 competencias en total, que, a su vez, se organizan hasta en seis niveles competenciales cada una. De este modo, se pretende una introducción progresiva de las competencias digitales en el profesorado en España, que implica al conjunto del sector de la educación.

En este trabajo pretendo analizar cómo he afrontado la introducción y uso de las TIC en mi docencia universitaria en materias de Arte y Cultura Visual, haciendo énfasis en el último 
periodo de adaptación virtual de la docencia por covid-19. Con ello, aportar resultados sobre aspectos metodológicos de la enseñanza y del aprendizaje en la introducción del uso de las TIC en la docencia. La adaptación virtual de la docencia universitaria en España por covid-19 la viví como una paradoja. Por un lado, la continuación con asignaturas que he impartido anteriormente y que no son nuevas para mí. Y, por otro, encontrarme en la situación de no poder hacer nada igual.

Numerosos trabajos recientes han puesto el foco en el estudio de las fortalezas y debilidades de las herramientas tecnológica en la didáctica de las artes (Sales-Romeu, Roig-Barrios y Marín-Suelves, 2019; Moral, Sánchez-Prada y Mercadal-Brotons y Sabbatella, 2017; MoralPérez y Villalustre-Martínez, 2009). En mi experiencia docente, uno de los primeros retos que enfrenté fue la relación pedagógica y la participación en este escenario de la docencia (híbrido y virtual), y que era nuevo para mí. Como dice Hernández-Hernández (2011): “Tener como referente la relación pedagógica nos lleva (...) a prestar atención a cómo se posibilitan los encuentros en los que se comparten subjetividades y saberes" (p.7). Entendí que era la ocasión de repensar las posibilidades de socialización e interacción virtual del y con el alumnado. Además, en el periodo de confinamiento y aislamiento que vivíamos, crear escenarios educativos de actividades compartidas y trabajo en grupo, me pareció que había cobrado aún más importancia.

Otro de los retos que enfrenté fue el de la alfabetización digital (Álvarez Rodríguez et al., 2019; González, 2012). Verdaderamente, este ya era un tema importante de formación antes de la pandemia. Pero quizá, ahora, ya no se trató de algo que afectaba transversalmente, sino que se convirtió en el tema principal. Observé que, en mi docencia, la búsqueda, selección, gestión y crítica de la información artística digital y sus fuentes era algo que iba a estar desde el principio hasta el final del trabajo de las asignaturas. Y, por tanto, fue la ocasión de que ampliara mi didáctica de la alfabetización digital para contenidos artísticos.

Finalmente, un último reto que enfrenté y quisiera destacar, fue la accesibilidad a las herramientas virtuales para la actividad docente de alumnado y profesorado (Lloyd, 2020;

Volumen 2. Número 2. Julio - Diciembre 2022 
Romo, 2017; Almenara, 2004). Este reto ha sido ampliamente compartido por toda la comunidad educativa, reconociéndose que existe una brecha digital de aparatos electrónicos y de conexión a internet. Esto afectaba tanto a los programas y herramientas informáticas, según licencias, descarga, uso y manejo; como también al acceso a la situación de aprendizaje prevista, según la posibilidad de alternar ventanas en el dispositivo electrónico de conexión en clase síncrona, la velocidad y capacidad durante la conexión a internet (no requerir grandes descargas durante una clase síncrona), etc.

\section{Metodología}

Este estudio lo abordo desde una metodología de investigación cualitativa de tipo descriptivoexploratoria. En este sentido, abordo el estudio de la transformación digital de la docencia en el uso de las TIC en la materia de Arte y Cultura Visual desde un enfoque socioeducativo, de acuerdo al contexto de adaptación virtual de la docencia que vivencié en la Universidad de Jaén en España, durante el último periodo de pandemia sanitaria por covid-19. Se adopta así una perspectiva auto etnográfica de la investigación orientada a la innovación docente y al cambio educativo (Cochran-Smith y Lytle, 2009; Bausela Herreras, 2004). La investigación transcurre en la misma actividad docente, tomando conciencia de las interacciones que se suceden en el conjunto del grupo social que constituye el hecho educativo y las personas implicadas (alumnado, profesorado, contexto, etc.).

La recogida de datos la he basado en técnicas auto etnográficas (Calva, 2018; Angrosino, 2012), de manera que he recogido como casos de estudio mis propias experiencias didácticas en mi ejercicio docente en arte y cultura visual. De forma inductiva, desarrollo una observación participante sobre la actividad docente y educativa que se va sucediendo, y en la tutorización del trabajo con el alumnado, detectando los momentos críticos del aprendizaje: dificultades, beneficios, etc. Recojo evidencias basadas en observaciones y grabaciones de las tareas educativas, respuestas emitidas por los participantes, expresiones y narrativas de las acciones desempeñadas en los procesos de enseñanza-aprendizaje (Zabalza, 2012). La herramienta principal de recogida de datos es el diario de campo, que posteriormente es 
revisado de forma crítica y respecto del conjunto del transcurso de las diferentes sesiones de trabajo docente, hacia los resultados de la investigación.

El periodo de estudio abarca desde 2016 hasta 2021, según he integrado dos años previos a la pandemia, hasta el último año académico que terminó el pasado mes de julio de 2021. La clasificación de la información se ha dirigido a dos aspectos principales: por un lado, de los contenidos artístico de la enseñanza y, por otro, de las actividades didácticas.

Para la muestra de estudio, he tomado como referencia mi experiencia docente en dos asignaturas, y según el histórico de actividades que trabajé con el alumnado para el periodo entre 2016 y 2021. De este modo, he integrado en la muestra desde dos años académicos previos a la pandemia (2016/2017 y 2017/2018) hasta el último año académico en pandemia (2020/2021). Las asignaturas han sido: Las Artes Plásticas y la Cultura Audiovisual en Educación Primaria del Grado en Educación Primaria; y Arte Infantil y Cultura Visual del Grado en Educación Infantil, ambas de la Universidad de Jaén en Jaén (Andalucía, España). Las Artes Plásticas y la Cultura Audiovisual en Educación Primaria es una asignatura de tipo obligatoria, con 9 créditos ECTS, que se imparte en el $2^{\circ}$ curso del Grado. Tiene un calendario lectivo de cuatro meses (septiembre-diciembre 2020). Se imparte en horario semanal de cuatro horas de teoría y cuatro horas de prácticas. Comprende cuatro competencias y seis resultados del aprendizaje, entre los que se incluyen: CFDD30 de Comprender los principios que contribuyen a la formación cultural, personal y social desde las artes; y CFDD32 de Adquirir recursos para fomentar la participación a lo largo de la vida en actividades musicales y plásticas dentro y fuera de la escuela. El total de alumnado matriculado fue de 55 alumnos/as, de los cuales, 29 fueron mujeres y 26 fueron hombres.

Arte Infantil y Cultura Visual es también una asignatura de tipo obligatoria, con 3 créditos ECTS, que se imparte en el $3^{\circ}$ curso del Grado. Tiene un calendario lectivo de dos meses (enero-febrero 2021). Se imparte en horario semanal de tres horas de teoría y tres horas de prácticas. Comprende cuatro competencias y tres resultados del aprendizaje, entre los que se incluyen: CFDD24 de Analizar los lenguajes audiovisuales y sus implicaciones educativas; y

Volumen 2. Número 2. Julio - Diciembre 2022 
CFDD25 de Promover la sensibilidad relativa a la expresión plástica y a la creación artística. El total de alumnado matriculado fue de 63 alumnos/as, de los cuales, 60 fueron mujeres y solo tres fueron hombres.

\section{Resultados}

En los primeros resultados encuentro que he experimentado un detrimento en el uso docente de los formatos plásticos, en un sentido objetual y matérico. Paulatinamente se ha reducido el trabajo de modalidades artísticas de creación de tipo escultórico, pictórico, de instalación, e incluso performático, para dar paso a otras de fotografía y audiovisuales de edición digital. Uno de los ejemplos ha sido el trabajo del proyecto de creación artística que anualmente he trabajado con el alumnado en el marco de la asignatura de Las artes plásticas y la cultura audiovisual en educación primaria. Este trabajo está integrado en el sistema de evaluación de la asignatura, con una puntuación parcial de 4 o 5 puntos del total de 10 puntos de la asignatura, según la propuesta didáctica de la asignatura de cada año. Consiste en la elaboración completa de un trabajo creativo de arte, pasando por las fases de ideación, simbolización material y ejecución técnica (dado el perfil educativo del alumnado, el proyecto también incluye un apartado de aplicación educativa). En los años anteriores a la pandemia por covid-19 (por ejemplo, en los años académicos 2016/2017 y del 2017/2018), la modalidad o formato artístico en que realizar el trabajo o la obra era libre, y cada grupo de trabajo de alumnos/as valoraba y elegía qué materiales prefería trabajar. En el conjunto de los trabajos entregados se reunían ejemplos tan variados como instalaciones en zonas del campus universitario, actuaciones performáticas, dibujos y pinturas. También los había de tipo digital, como series de fotografía o video-creaciones.

En los dos últimos años de pandemia (2019/2020 y 2020/2021), los medios de producción y postproducción se redujeron a los de edición digital (de fotografía, mayoritariamente). Un primer caso es el del trabajo de un fotomontaje. Este comprendió dos fases de trabajo principales: primero, el alumnado realizó una búsqueda de imágenes en colecciones digitales de museos de arte; y, a continuación, intervenían al menos una de las obras (imagen de la 
obra) con técnicas digitales de fotomontaje. Otro caso fue también el proyecto de creación artística. En lugar de la variedad de las modalidades de arte y de su libre elección que se permitieron en los años anteriores, en estos últimos se determinó una única modalidad, y que fue de realizar una cartografía visual.

Un último caso es el de la práctica de objeto escultórico. Esta práctica la he trabajado con el alumnado desde hace varios años, incluso antes de la pandemia. Consiste en reunir una serie de objetos preexistentes que están presentes en nuestra vida cotidiana (7-10 objetos), y de manera que todos ellos versen o tengan que ver en torno a un mismo tema o asunto en común (tan solo se consideran criterios de exclusión para la selección de estos objetos que el alumnado no pueda transportarlo fácilmente y que sean objetos frágiles). Una vez reunidos, el alumnado debía componer un mismo objeto escultórico con todos ellos, a modo de assemblage. En los años anteriores a la pandemia, el alumnado realizaba esta práctica en grupos pequeños de trabajo de tres o cuatro personas; traían la relación de objetos al aula y lo componían en la misma clase; se realizaban tres y cuatro revisiones hasta la obra final (con ello, el alumnado trabajaba la simbolización, la materialidad, etc.); al terminar, los resultados se exponían y explicaban.

Pero en los dos últimos años de pandemia se dieron dos condiciones a esta práctica: la imposibilidad tanto de trabajar en grupo como de compartir materiales de trabajo en el aula; así como los periodos de modalidad $100 \%$ virtual de la docencia, en la que directamente las clases fueron por videoconferencias síncronas. Así, la práctica se adaptó de la siguiente manera: en lugar de trabajar en grupo, el alumnado la realizó de manera individual; en lugar de transportarse los objetos hasta el aula, la composición se realizó en el ámbito doméstico o particular de cada alumno/a; en lugar de exponer físicamente los trabajos finales, se documentaron con fotografías y estas se visualizaron y mostraron de manera compartida.

Respecto de los recursos TIC empleados en los resultados anteriores de adaptación virtual de la docencia, he recogido hasta tres tipos de herramientas principales que he empleado en la 
docencia: unas de postproducción digital de imágenes $\left(\right.$ Gimp $^{2}$ y Sumo Paint ${ }^{3}$ ), otras de búsqueda especializada de imágenes de arte (portales web de museos y de otras entidades formales); y, finalmente, también de visualización y compartición digital de los trabajos (Google Currents, Grupo privado de Facebook).

Gimp y Sumo Paint son un software de edición digital de imágenes. Para seleccionar este tipo de herramientas, tuve en cuenta tres criterios principales: la gratuidad del uso de la herramienta para el alumnado, el diseño simplificado e intuitivo de la interfaz del software. y una alta compatibilidad con sistemas operativos y capacidades medidas de los dispositivos electrónicos (PC Windows, Mac, tableta Android, iPad, smartphone Android, iPhone, etc.). Esas dos cumplen con estos criterios. Sumo Paint, a su vez, también se ofrece como extensión de Google Chrome, por lo que se puede utilizar directamente desde el navegador de internet. Para la búsqueda especializada de imágenes de arte, introduje tres herramientas digitales: Google Arts \& Culture ${ }^{4}$, los portales web de los museos nacionales de arte en España (Museo

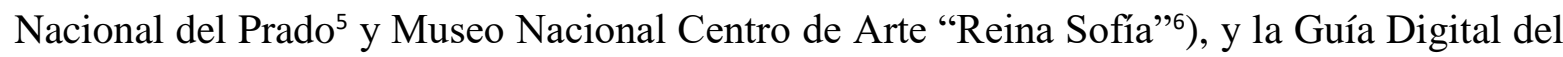
Patrimonio Cultural de Andalucía ${ }^{7}$. En los criterios para elegir estas herramientas, de nuevo tuve en cuenta la gratuidad, acceso disponible en línea. A su vez, en esta ocasión también fue importante reunir bancos de imágenes que abarcaran diversos ámbitos (universal, internacional, nacional y local). De esta forma, diseñé varias dinámicas para que el alumnado trabajara la búsqueda especializada de imágenes en estos. Por ejemplo, introduje Google Arts \& Culture, en la docencia para realizar un trabajo de comparación y lectura crítica. Esta consistió en que cada alumno/a eligiera un motivo artístico (figuras de mujer, animales, razas humanas, etc.), y seleccionaran varias imágenes que incluyeran o refirieran ese motivo, y establecer comparaciones entre sí. En otras ocasiones, las introduje como fase previa a una práctica de creación. Por ejemplo, en el trabajo práctico de fotomontaje -al que ya aludí en resultados anteriores en este mismo trabajo-, el alumnado partía de una primera imagen de

\footnotetext{
2 http://www.gimp.org.es/

${ }^{3}$ https://sumo.app/

${ }^{4}$ https://artsandculture.google.com/time?date $=1940$

${ }^{5} \mathrm{https}$ ///www.museodelprado.es/coleccion/linea-del-tiempo?pInit=1100-1-1\&pEnd=2120-1-1

${ }^{6}$ https://www.museoreinasofia.es/\#

${ }^{7}$ https://guiadigital.iaph.es/inicio
} 
arte que previamente seleccionaba dentro de alguna de las colecciones digitales de museos nacionales de arte y del patrimonio de Andalucía, sobre esta misma realizaban una intervención artística basada en técnicas de fotografía digital.

En los años académicos anteriores a la pandemia por covid-19, utilicé catálogos de exposiciones de arte celebradas en el entorno próximo de la Universidad de Jaén. Estos son libros impresos, comúnmente en pequeño formato. Introducía en el aula una amplia cantidad, de manera que el conjunto de alumnos/as de la clase podía consultar, coger y cambiar entre una cierta variedad de contenidos y propuestas artísticas. Para un carácter más internacional de los contenidos, también utilicé en varias ocasiones un juego de cartas de arte, llamado "The Game of Art"8, que reúne alusiones a los/as artistas principales del ámbito internacional, según el reconocimiento de la crítica artística de la Historia del Arte.

Para finalizar, las herramientas digitales para la presentación y exposición de los trabajos que utilicé fueron: Google Currents, Grupo privado de Facebook. En la adaptación virtual de la docencia encontré la necesidad de poder compartir y mostrar de manera simultánea el trabajo que se realizaba en la conexión virtual de la clase. El problema residía en que, con la opción de compartir pantalla que sí disponen las herramientas de conexión de videoconferencia, tan solo se visualiza el trabajo de un/a alumno/a de la clase. Sin embargo, la necesidad era que toda la clase pudiera ver todos los trabajos a la vez (como cuando en el aula presencial se mostraban los trabajos en su carácter objetual). Para ello, encontré una solución en el uso de las redes sociales Google Currents y Grupo privado de Facebook. En ambas, se pueden publicar varios archivos de manera simultánea, así como disponer de una visualización inmediata para todos los/as usuarios/as del grupo.

\footnotetext{
${ }^{8}$ https://www.laurenceking.com/product/the-art-game-new-edition/ 


\section{Discusión de resultados y conclusiones}

La discusión de los resultados la enfoco según las fortalezas y las debilidades de las metodologías docentes de esta experiencia. En primer lugar, abordaré las fortalezas y, a continuación, las debilidades. Respecto de las primeras, la principal se refiere a que el uso de las TIC en mi experiencia de enseñanza-aprendizaje en la materia de arte y cultura visual ha favorecido la implementación de metodologías dialógicas y participativas. Considero oportuno hacer un destacamento especial de este aspecto, dado que estas metodologías es uno de los pilares esenciales para una educación en competencias, y que, a su vez, constituye el marco teórico principal de las políticas educativas actuales (Valle-López y Manso-Ayuso, 2013). En este mismo sentido, la segunda fortaleza que he encontrado ha sido que el uso de las TIC también ha favorecido una mayor autonomía en el aprendizaje del alumnado. Esto está relacionado con la tercera fortaleza, que se refiere a un mayor acceso a las herramientas de trabajo en la materia y a un mejor acceso a referencias artísticas. Por otro lado, respecto de las debilidades, encuentro especialmente que el uso de las TIC en esta docencia ha supuesto una disminución de todos los aspectos corporales, tanto en lo que respecta a la implicación corporal en la elaboración del trabajo artístico, como también en lo que respecta a las relaciones sociales con los demás y con el entorno. Veamos a continuación estas cuestiones con mayor detalle.

En los resultados anteriores encuentro que, más tradicionalmente, planifiqué la metodología didáctica de mi docencia según dos tipos principales de actividades: unas más de tipo clase magistral y, otras, más de tipo práctica. De esta forma, mi docencia transcurría entre la introducción de ideas, contenidos y cuestiones y la resolución de problemas o aplicación práctica de estos (Tirado-de la Chica, 2021). Mientras no interrumpí la modalidad presencial de mi docencia, esta combinación de actividades me resultó efectiva. Sin embargo, cuando experimenté una adaptación a modalidad $100 \%$ virtual de mi docencia desde marzo de 2019, y en las circunstancias tan repentinas y sorpresivas que nos sobrevinieron a todos/as los/as docentes en aquel momento, encontré que esa combinación de actividades ya no me serviría.

Volumen 2. Número 2. Julio - Diciembre 2022 
En lugar de actividades más del tipo clase magistral para el trabajo de las clases teóricas de las asignaturas, basé la relación pedagógica en diálogos y preguntas que estuvieran dirigidos hacia la resolución de dudas, encrucijadas o problemas, que pudieran resolverse en periodos cortos de tiempo (dos o tres preguntas por conexión síncrona de clase). Se traban de consultas breves que se iban sucediendo, y que en ocasiones se respondían más directamente desde nuestras opiniones o primeras ideas y, otras, después de consultar una información específica y breve seleccionada para la clase. Así, por ejemplo, para la introducción de un nuevo tema, propicié lluvias de ideas y expresiones de nuestros conocimientos previos. Para ello, utilizamos formatos diversos. En ocasiones, de forma oral directamente: en la conexión de videoconferencia de la clase síncrona, el alumnado podía utilizar, tanto la herramienta de "levantar la mano" para solicitar turno de intervención, como escribir en el chat de la conexión. Pero, también, otros formatos visuales, como realizar un primer dibujo o mapa conceptual de ideas (Yenawine, 2013). También de comparar imágenes o videos de ejemplos y elaborar un conocimiento descriptivo e interpretativo al respecto (Google Currents y Grupo privado de Facebook). O consultar bases de datos específicas de arte y educación artística y encontrar otros ejemplos representativos de nuevas ideas (Google Art \& Culture, Aplicación de línea del tiempo del Museo Nacional del Prado, Herramienta de búsqueda de la página web del Museo Nacional del Centro de Arte "Reina Sofía", entre otros); consultar y extraer una información sobre fuentes específicas, para elaborar un conocimiento explicativo. En esta relación pedagógica, hablábamos sobre nuestras ideas y experiencias respecto de los temas de aprendizaje, poníamos en duda lo que pensábamos y tratábamos de elaborar nuevas relaciones de sentido, de acuerdo también a una determinada información disponible.

Ello entronca con las metodologías dialógicas y participativas para una educación en competencias: resolución de ejercicios y problemas, aprendizaje orientado a proyectos, contrato de aprendizaje, etc. (Díaz, 2005; Fernández-March, 2006). De esta forma, el uso de las TIC ha favorecido una mayor autonomía del alumnado en su proceso de aprendizaje. Esto tiene que ver con el enfoque que he dado a mi docencia en mi rol de docente -según explicaba anteriormente-, pero también con el mayor acceso tanto a la información como a las herramientas de trabajo artístico que han permitido las TIC en mi docencia. Los resultados

Volumen 2. Número 2. Julio - Diciembre 2022 
anteriores indican una relación de herramientas digitales referidas tanto a la edición digital de imágenes como a la búsqueda de información especializada en arte (Gimp, Sumo Paint, Google Art \& Culture, aplicaciones web de museos nacionales de arte y del patrimonio local). Todas estas son de acceso abierto y gratuito en internet. No requieren suscripción ni pago, además de que tienen interfaz sencilla y fácil de utilizar -al menos para jóvenes de la Generación Z, que actualmente constituyen la mayoría del alumnado universitario (MedinaDomínguez, 2019). En este sentido, presentan un mayor acceso frente a los recursos físicos tradicionales: de materiales y técnicas artísticas (pintura, dibujo, escultura, etc.), para los que el alumnado debe hacer los gastos de compra de materiales y utensilios; y también de biblioteca o hemeroteca para la consulta y recogida de información artística, que implica desplazamientos, gastos de transporte, mayor dedicación temporal, etc. Así, por ejemplo, buena parte del alumnado de la Universidad de Jaén no reside en la misma ciudad de Jaén, sino que diariamente realiza trayectos de ida y vuelta entre otros municipios o pueblos y la capital. Además, existe un importante hándicap en la centralización de la información en las zonas principales académicas, de manera que la cantidad de recursos bibliográficos disponibles en las universidades más pequeñas son menores también. Por tanto, utilizar recursos digitales en abierto y gratuitos tanto para la edición de trabajos artísticos como para la búsqueda y consulta de información artística especializada, democratiza y facilita el acceso de todo el alumnado y, de este modo, los/as docentes nos encontramos en una situación didáctica mucho más favorable para que el alumnado trabaje de manera autónoma con estos recursos.

Por otro lado, las debilidades encontradas en los resultados se refieren a una disminución de la implicación corporal en el aprendizaje. Mendoza-Castillo (2020) dice que "no se aprende sólo desde la cabeza, sino también desde el cuerpo. Aunque el centro de procesamiento de toda la información que sentimos y percibimos es el cerebro, todo el cuerpo manda señales de las experiencias. (...) no por tratarse de trabajo escolar debe pensarse que sólo leyendo y escribiendo con ayuda de los dispositivos se aprende; por el contrario, el cuerpo, el movimiento, los sentidos, las emociones están involucrados en cómo cada persona internaliza la información" (p.349).

Volumen 2. Número 2. Julio - Diciembre 2022 
En este sentido, el uso de los recursos TIC en mi docencia han reducido la capacidad de subjetivación a través de la condición presencial y vital de los cuerpos, así como de la capacidad de relaciones con los ámbitos sociales y del entorno. En los resultados recogí casos de actividades didácticas de trabajos artístico plástico y otras de trabajo digital de edición de imágenes. En las primeras, toda la actividad sucede a través de los materiales plásticos: empezando por la adquisición de estos, su manipulación, etc. En estas, el alumnado primero diseña una primera propuesta del trabajo artístico, decide el formato y los materiales plástica que necesita. Entonces planea cómo los va a obtener: pedir préstamo, reciclar, comprar, etc. Cada una de estas maneras de adquisición provoca que el alumnado se desplace a diferentes lugares del entorno, desarrollo una comunicación con diferentes agentes del entorno, etc. Estas relaciones transcurren intermitentemente a lo largo de todo el proceso de trabajo, según las necesidades que deben ir resolviendo para la ejecución del trabajo artístico.

En el trabajo digital de imágenes, sí hay una primera fase de ejecución física y presencial, según la grabación de fotografías o videos primarios, pero, después, el trabajo de postproducción de estos trabajos académicos se realiza por ordenador y, además, comúnmente el alumnado utiliza un mismo ordenador para todo el trabajo de postproducción. Durante el periodo de adaptación $100 \%$ virtual de la docencia, el alumnado no realicé físicamente ni la grabación de imágenes, sino que también fueron recogidas de bases de datos digitales, o realizadas en el entorno doméstico de cada alumno/a de manera individual. Así, vemos cómo el uso de las TIC presenta la debilidad de reducir las experiencias de aprendizaje que se derivan de las actividades físicas y en el entorno.

En conclusión, la eficacia de la docencia en el uso de las TIC en materias de arte y cultura visual y, en general, en el Área de Arte y Humanidades, reside en que el uso de los recursos y herramientas digitales vayan acompañadas junto con metodologías dialógicas y participativas de la enseñanza y del aprendizaje. Cambiar el material docente, pero continuando con los mismos sistemas docentes más tradicionales, supone no aprovechar todas las oportunidades que ofrecen las TIC: de acceso a la información, de implementación de las técnicas, del metaconocimiento, etc. Asimismo, el uso de las TIC en la docencia también se favorece el 
aprendizaje autónomo del alumnado, al disponer en su propio ordenador o dispositivo de una amplia relación de herramientas y recursos bibliográficos, aprovechando, en este sentido, la disponibilidad de recursos electrónicos de acceso abierto y gratuitos. Sin embargo, el uso de las TIC en la docencia también supone debilitar las experiencias de aprendizaje a través de la corporeidad y que tienen que ver con relacionarse con el entorno. En este sentido, se hace necesario combinar de manera sostenible el uso de las TIC con otras actividades didácticas que desplacen al alumnado por el entorno y los lugares, provoquen dirigirse y comunicarse con diferentes agentes, localizar en el entorno recursos, etc.

\section{Referencias}

Angrosino, M. (2012). Etnografía y observación participante en investigación cualitativa. Ediciones Morata, S. L.

Almenara, J. C. (2004). Reflexiones sobre la brecha digital y la educación en F. J. Soto y J. Rodríguez (Coords.): Tecnología, educación y diversidad: retos y realidades de la inclusión social (pp.23-42). Consejería de Educación y Cultura del Gobierno de Murcia.

Álvarez Rodríguez, M.V., Hernández González, G., Hortelano Mínguez, L.A., Núñez Izquierdo, S., Paliza Monduate, M.T., Panera Cuevas, F.J., y Rodríguez Bote, M.T. (2019). Una tentativa de alfabetización informacional para alumnos de grado y posgrado en la rama de conocimiento de Artes y Humanidades. En R. Roig-Vila, (ed.), Investigación e Innovación en la Enseñanza Superior: nuevos contextos, nuevas ideas (pp.899-908). Octaedro. http://hdl.handle.net/10045/98731

Bausela Herreras, E. (2004). La docencia a través de la investigación-acción. Revista Iberoamericana de Educación, 35(1), 1-9. https://doi.org/10.35362/rie3512871

Calva, S. M. B. (2018). Auto etnografía en la universidad: un ejercicio de enseñanzaaprendizaje. Investigación Cualitativa, 3(1), 16-29. 
Cochran-Smith, M., y Lytle, S. L. (2009). Inquiry as stance: Practitioner research for the Next generation. Teachers College Press. http://ojs.revistainvestigacioncualitativa.com/index.php/ric

DGECT. (2020). Resolución de 2 de julio de 2020, de la Dirección General de Evaluación y Cooperación Territorial, por la que se publica el Acuerdo de la Conferencia Sectorial de Educación sobre el marco de referencia de la competencia digital docente. B.O.E., núm. 191, de 13 de julio de 2020, pp.50638-50668. https://www.boe.es/eli/es/res/2020/07/02/(2)

Díaz, M. M. (Dir.). (2005). Modalidades de Enseñanza Centradas en el Desarrollo de Competencias: orientaciones para promover el cambio metodológico en el Espacio Europeo de Educación Superior. Ed. Universidad de Oviedo. https://www2.ulpgc.es/hege/almacen/download/42/42376/modalidades_ensenanza_compete ncias_mario_miguel2_documento.pdf

Fernández-March, A. (2006). Metodologías activas para la formación de competencias. Educatio siglo XXI, 24, 35-56. https://revistas.um.es/educatio/article/view/152

González, N. (2012). Alfabetización para una cultura social, digital, mediática y en red. Revista Española de Documentación Científica, número monográfico, 17-45. https://doi.org/10.3989/redc.2012.mono.976

Hernández-Hernández, F. (2011). Prestar atención a la relación pedagógica como alternativa a la concepción de innovación en la docencia que actúa como dispositivo para construir un modo de identidad de estudiantes y profesores en la universidad en F. Hernández (Coord.), Pensar la relación pedagógica en la universidad desde el encuentro entre sujetos, deseos y saberes. Universitat de Barcelona. http://hdl.handle.net/2445/20946

INTEF. (2017). Marco Común de Competencia digital Docente. https://bit.ly/3tApUxf 
Medina-Domínguez, M. C. (2019). Formación en competencias a lo largo de la vida y diversidad educativa en M. C. Domínguez-Garrido et al. (Coord.), Actas del XXIV Congreso $\begin{array}{lllll}\text { InterEstraTIC } & 2019 \quad \text { (pp.145-151). } & \text { Ed. } & \text { UNED. }\end{array}$ spacio.uned.es/fez/view/bibliuned:424-Mlcacheiro-0001

Mendoza-Castillo, L. (2020). Lo que la pandemia nos enseñó sobre la educación a distancia. Revista Latinoamericana de Estudios Educativos, L, 343-352. Disponible en: https://www.redalyc.org/articulo.oa?id=27063237028

Moral, M. T., Sánchez-Prada, A., Mercadal-Brotons, M. y Sabbatella, P. (2017). Análisis de contenido y análisis DAFO en una investigación cualitativa sobre la Musicoterapia en España. CIAIQ, 3, 403-412. https://proceedings.ciaiq.org/index.php/ciaiq2017/article/view/1182

Moral-Pérez, M. E. del, Villalustre-Martínez, L. (2009). Evaluación de prácticas docentes universitarias desarrolladas en entornos virtuales. Pixel-Bit: Revista de medios y educación, 34, 151-163. https://recyt.fecyt.es/index.php/pixel/article/view/61373

Lloyd, M. W. (2020). Desigualdades educativas y la brecha digital en tiempos de COVID-19 en H. Casanova-Cardiel (Coord.), Educación y Pandemia: una visión académica (pp.115121). IISUE/UNAM. https://www.iisue.unam.mx/investigacion/textos/educacion_pandemia.pdf

Romo, N. M. (2017). Las TIC y los escolares del medio rural, entre la brecha digital y la educación inclusiva. Bordón. Revista de pedagogía,69(3), 41-56. https://doi.org/10.13042/Bordon.2017.52401

Sales-Romeu, C. de, Roig-Barrios, A., y Marín-Suelves, D. (2019). Análisis DAFO de herramientas tecnológicas para el área de Música. Revista DIM: Didáctica, Innovación y Multimedia, 37, 1-10. https://ddd.uab.cat/record/206275 
Tirado-de la Chica, A. (2021). Una didáctica de museos de arte: exploración libre y resignificación en O. Buzón-García, C. Romero-García y A. Verdú-Vázquez (Coord..), Innovaciones Metodológicas con TIC en Educación (pp.1822-1843). Dykinson, S. L.

Valle-López, J., y Manso-Ayuso, J. (2013). Competencias clave como tendencia de la política educativa supranacional de la Unión Europea. Revista de Educación, Extraordinario, 12-33. https://doi.org/10.4438/1988-592X-RE-2013-EXT-255

Yenawine, P. (2013). Visual Thinking Strategies Using Art to Deepen Learning Across School Disciplines. Harvard Education Press.

Zabalza Beraza, M. A. (2012). El estudio de las "buenas prácticas” docentes en la enseñanza universitaria. Revista de Docencia Universitaria, 10(1), 17-42. https://dialnet.unirioja.es/descarga/articulo/4020162.pdf 